\section{Moloney Leukaemia Virus as a Helper in retrieving Friend Virus from a Non-infectious Reticulum Cell Sarcoma}

A Transplantable reticulum cell sarcoma induced by Friend virus (FV) and subsequently grown in tissue cul. ture no longer contained detectable infectious FV, and was incapable of inducing either protective or viral neutralizing antibodies, ${ }^{1,2}$. This tumour (FVTC' $)$ has been maintained in vitro for several years, and except for its apparent lack of virus it behaves in an identical way to the tumour from which it originated ${ }^{3}$. It is highly specific for syngeneic $\mathrm{BALB} / \mathrm{c}$ mice and produces tumours morphologically indistinguishable from other reticulum cell sarcomas induced by $\mathrm{FV}$.

FV, however, in certain conditions, can also induce lymphatic leukaemia from which transplantable lymphomas may be derived ${ }^{4,5}$. This capability was shown not to be caused by FV itself but by a lymphatic leukaemia virus (LLV) which was invariably associated with $i t^{6}$. LLV could be readily separated from FV, inducing only lymphatic leukaemia. All offorts to obtain FV free of LLV failed, however. Further, the two agents could not be distinguished immunologically so it was concluded that FV was probably defective and required LLV as a helper virus. Preliminary experiments indicated that it was possible to retrieve infectious FV from the FVTCT with LLV (our unpublished results). But, because of the close association between the two viruses, the possibility remained that the FV which was recovered could have arisen from residual contamination of the $\mathrm{LLV}$ with $\mathrm{FV}$.

Moloney leukaemia virus (MLV), which is closely related immunologically to FV (ref. 7), induces lymphatic leukaemia which is grossly and morphologically indistinguishable from the disease induced by L.LV. It was possible that the relationship between $\mathrm{FV}$ and $\mathrm{MLV}$ was mediated by LLV and that the latter and MLV were actually the same or very similar viruses. Huebner et al. ${ }^{8}$ had shown that Moloney sarcoma virus could be rescued by MLV and several other viruses including FV. It was therefore more than likely that if the FVTCT contained defective FV it could be rescued by MLV as well as LLV.

Table 1. RECOVERY OF INFECHOUS FRIEND VIRTS FROM NON-INEECTOCS TCMOCR USIYG MOLONEY LECKAEMIA VIRTS AS HELPER

$$
\begin{array}{ccc} 
& \text { No. of mice } & \text { No, with } \\
\text { No. with lym- }
\end{array}
$$

Inoculum inoculated Friend discase phatic leukaemia

30
16
41
$3+$

30
16
0
0

Now cells. Resultant tumour extracts were inoculated into newborn mice.

* Tumours from mice inoculated with $M L V$ and FVTCT transplanted into another group of mice. Extracts of tumours from the latter were inoculated into newborn mice.

+ Extracts of tumours from mice inoculated with FVTCI only inoculated into newborn mice.

\$ Extracts of MULV only inoculated into newborn mice.

A group of nowborn BALB/c mice was inoculated intraperitoneally with MLV from a pool received from Dr J. B. Moloney. Thirty-six days later they received a subcutaneous injection between the scapulae of $10^{6}$ viable tumour cells of the non-infectious FVTCT. Controls received either MLV or tumour cells alone. Four mice which had received MLV and FVTCT were killed 43 to 48 days Iater. A 20 per cent cell-free extract was prepared from each tumour and inoculated intraperitoneally into newborr $\mathrm{BALB} / \mathrm{c}$ mice. By the fifteenth day after inoculation most of the mice had obviously enlarged spleens. Deaths started to occur by the twenty-fifth day and the remainder were killed between the twentysixth and thirty-fifth day when moribund. All thirty mice had enlarged, blood filled, sac-like spleens typical of Friend disease, which was confirmed histologically. One mouse also had microscopic evidence of early lymphatic leukaemia. In addition, the tumour from one mouso which had recoived MLV plus FVTCT was transplanted intraperitoncally into another group of untreated weanling BALB/c mice. Ten per cent cell-free extracts were made from two of the resultant reticulum cell sarcomas and each inoculated into a litter of ten and six newborn BALB/c mice, respectively; all developed typical Friend disease.

Extracts of tumours from five mice which had received FVTCT only were inoculated into forty-one newborn BALB/c mice. When killed 193 days later, none of these mice had any signs of disease either grossly or histologically. All of a group of thirty-four newborn BALB/c mice inoculated only with the pcol of MLV developed lymphatic leukaemia with a latent period of 10 to 12 weeks (Table 1).

It is concluded that the Friend virus-induced reticulum cell sarcoma which has been maintained for several years in vitro contained defective, non-infectious Friend virus, which could be retrieved in vivo by the addition of Moloney leukaemia virus. The latter probably acted to supply the genetic information required by Friend virus for the synthesis of its protein coat, resulting in infectious virus.

This work was supported by a US Public Health Service grant from the National Cancer Institute.

\section{A. Howard Fieldosteel} Carolie Ktrahara

Stanford Research Institute,

Menlo Park, California 94025.

Peter J. Dawson

Department of Pathology,

University of Oregon Medical School,

Portland, Oregon.

Received August 1, 1969

Fieldsteel, A. H., Dawson, P. J., and Scholler, J., J Nat Cancer Inst., 36, $71(1966)$.

${ }^{2}$ Fieldsteel, A. H., Kurahara, C., and Dawson, P. J., Cancer Res. (in the press).

Dawson, P. J., Fieldsteel, A. H., and Bostick, W. L., Cancer lies., 23, 349 (1963)

${ }^{4}$ Mirand, E. A., and Grace, J. T., Virology, 1\%, 364 (1962).

5 Dawson, P. J., Rose, W. M., and Fieldsteel, A. H., Brit. J. Cancer, 20, 114 (1966).

"Dawson, P. J. Tacke, R. B., and Fieldsteel, A. H., Erit. J. Cancew, 22, 569 (1968)

"Old, L. J., Boyse, E. A., and Stockert, E., Nature, 201, 777 (1964)

${ }^{8}$ Huebner, R. J., Hartley, J. W., Rowe, W. P., Lane, W. T., and Capps, W. I.. Proc. US Nat. Acad. Sci., 56, 1164 (1966).

\section{Lysosomes in Human Placenta}

SrNce their discovery ${ }^{1}$, lysosomes have been described in many tissues. Hore I report the presence of lysosomes characterized by staining with acridine orange ${ }^{2,3}$ and assays of the concentration and latency of acid phosphatase in the "lysosomal" pellet, in human term placenta.

Compared with other tissues from which lysosomes have? been obtained, the human placenta is an extremely fibrous organ and it is difficult to obtain preparations suitable for differential centrifugation using conventional methods of homogenization. The relatively new technique of pressure homogenization in a nitrogen born $b^{4}$ has enabled me to obtain a placental homogenate which on differential centrifugation in a zonal rotor gives a clean preparation of lysosomes.

A freshly delivered placenta was immersed in ico cold $0.25 \mathrm{M}$ sucrose solution buffered with tris to $p \mathrm{H} 7 \cdot 4$. The umbilical vessels were cannulated and the same solution (2 1.) was used for perfusing the foetal side of the placenta to remove the red blood cells. This took about $1 \mathrm{~h}$. The maternal side of the placenta was oxamined and adhering blood and blood clots removed if necessary by further immersions in the solution. Areas free of calcium deposits and gross infarcts were nipped off in small pieces and about $20 \mathrm{~g}$ of tissue was forced through a steel mesh $(1 \cdot 3 \mathrm{~mm}$ 